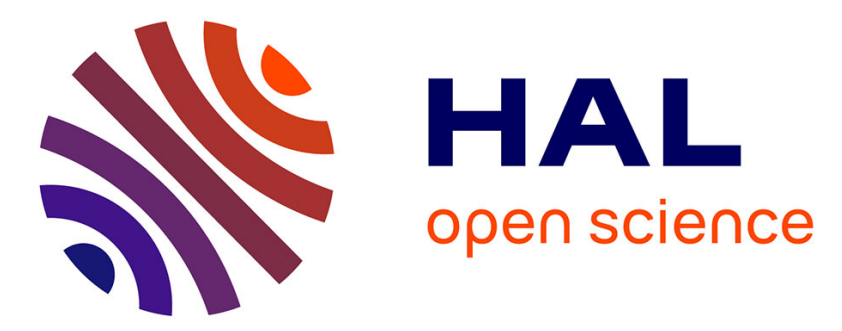

\title{
Scanning X-ray scattering of mouldings from semicrystalline polymers
}

P. Zipper, A. Jánosi, E. Wrentschur

\section{To cite this version:}

P. Zipper, A. Jánosi, E. Wrentschur. Scanning X-ray scattering of mouldings from semicrystalline polymers. Journal de Physique IV Proceedings, 1993, 03 (C8), pp.C8-33-C8-36. 10.1051/jp4:1993807 . jpa-00252226

\section{HAL Id: jpa-00252226 https://hal.science/jpa-00252226}

Submitted on 1 Jan 1993

HAL is a multi-disciplinary open access archive for the deposit and dissemination of scientific research documents, whether they are published or not. The documents may come from teaching and research institutions in France or abroad, or from public or private research centers.
L'archive ouverte pluridisciplinaire HAL, est destinée au dépôt et à la diffusion de documents scientifiques de niveau recherche, publiés ou non, émanant des établissements d'enseignement et de recherche français ou étrangers, des laboratoires publics ou privés. 


\title{
Scanning X-ray scattering of mouldings from semicrystalline polymers
}

\author{
P. ZIPPER, A. JÁNOSI and E. WRENTSCHUR \\ Institute of Physical Chemistry, University of Graz, Heinrichstrasse 28, 8010 Graz, Austria
}

The layered structure of plastic parts injection-moulded from industrial polypropylenes under varying processing conditions was studied by scanning small-angle and wide-angle $X$-ray scattering measurements on cross-sections of the parts. The analysis of the data in terms of apparent crystallite sizes, several parameters characterizing the distribution and orientation of different types of crystallites, and long periods is demonstrated by means of selected representative examples.

\section{Introduction}

The cross-section of plastic parts extruded or injection-moulded from semicrystalline polymers is not homogeneous but exhibits a sandwich-like architecture [1-3]. Details of this layered structure depend on the processing conditions to a high degree and may also vary considerably within the mouldings with increasing distance from the gate. The elucidation of the morphology and texture in the mouldings is of importance because of the relations between processing conditions, structure, and end use properties. X-ray methods have been used in different approaches (e.g., [1-3]) for studying the layered structure.

Recently position-resolved X-ray scattering, performed by scanning the cross-section of plastic parts with a fine X-ray beam aligned parallel to the surface of the parts and measuring the intensity of scattering as a function of position in the cross-section, was shown to be a potent tool for the characterization of the parts in terms of interior structure and texture [4-6].

\section{Experimental}

In our experimental setup the X-ray beam is collimated by means of a conventional Kratky camera to a line-shaped cross-section (about 60 $\mu \mathrm{m} \times 2 \mathrm{~mm}$ at the sample); the same setup is used both for SAXS and WAXS experiments. The narrow width of the beam enables a high resolution of position along the normal to the surface. For scanning, the sample is moved in steps of 10 or $20 \mu \mathrm{m}$ through the X-ray beam. Scattered radiation is registered by means of a linear position-sensitive detector (500 channels, aperture of the detector about $10^{\circ}$ ). For some preliminary SAXS experiments a proportional detector was used. The samples investigated in this study stem from rectangular plates $(230 \mathrm{x}$ $70 \times 2 \mathrm{~mm}$ ) injection-moulded from industrial polypropylenes Daplen KS10 and PT55 (PCD, Linz). Samples were cut from each plate at different distances from the gate and were investigated with different directions of the primary beam (normal, parallel, antiparallel to the direction of flow).

\section{Results}

Some results of WAXS measurements on cross-sections are shown in the figures. Fig. 1 shows the scattering intensities as measured, namely as scattering curves vs. the distance from the surface of the sample. Alternatively we 


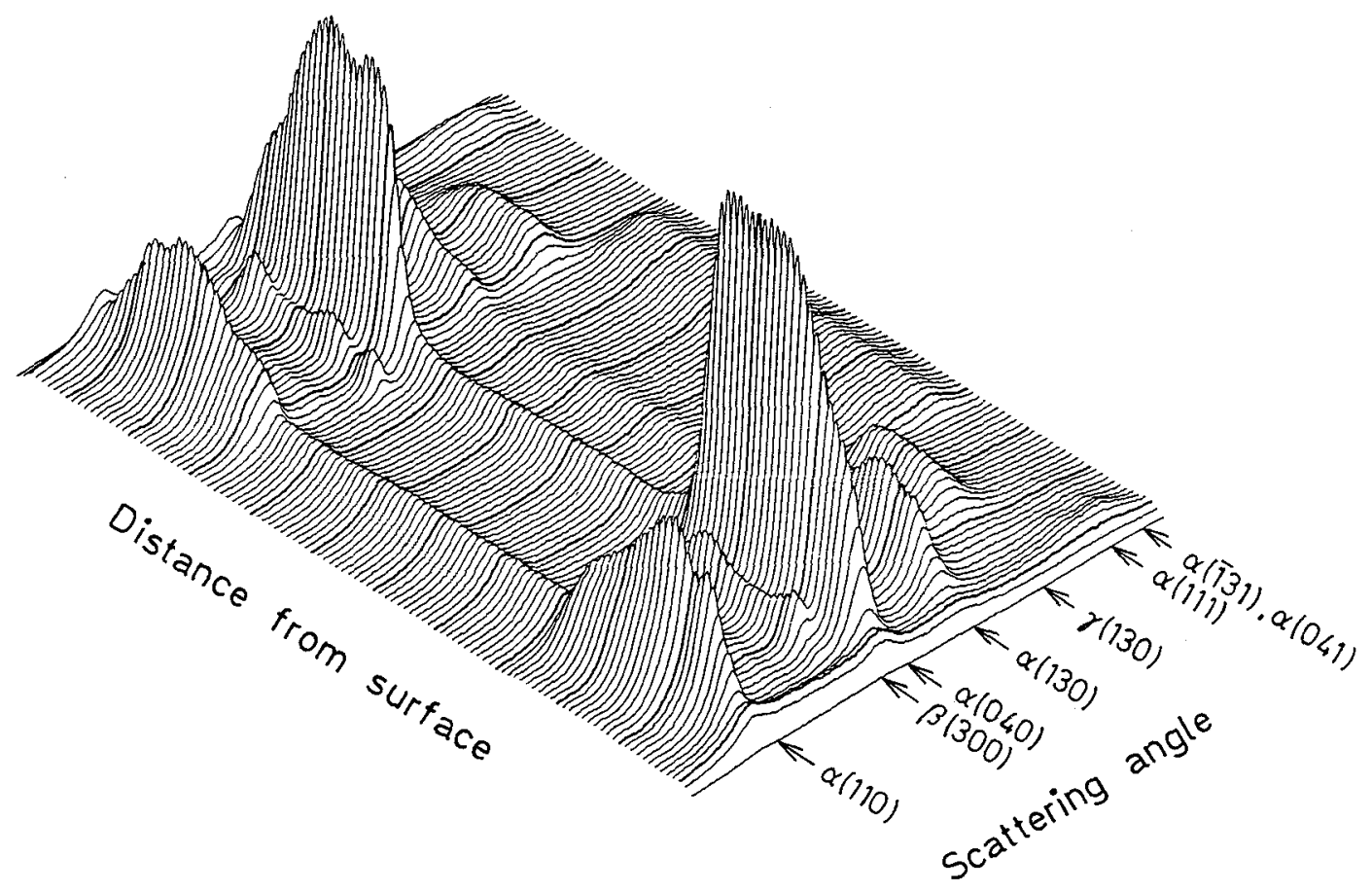

Fig. 1: WAXS curves (intensity as a function of scattering angle) plotted vs. the distance from surface. The sample was cut from a PP KS10 plate (thickness $\approx 2.1 \mathrm{~mm}$; processing conditions: melt temperature $200{ }^{\circ} \mathrm{C}$, mold temperature $20^{\circ} \mathrm{C}$, front velocity $100 \mathrm{~mm} / \mathrm{s}$, maximum pressure $1559 \mathrm{bar}$ ) at a distance of $100 \mathrm{~mm}$ from gate. The primary beam was directed normal to the direction of flow, the sample was moved through the beam in steps of $20 \mu \mathrm{m}$ from surface to surface. The intensity map of the crosssection displays reflections due to different crystallite modifications: $\alpha, \beta, \gamma$; the pertaining indices are shown. The pronounced difference in intensities between the surface and the core region signals a high degree of orientation in the surface layers.

often plot our data as scattering profiles (intensity as a function of the distance from surface) vs. scattering angle. The visual inspection of these intensity maps already delivers valuable information on the layered architecture in the crosssection, e.g. by revealing the presence and distribution of different polymer modifications or by providing a rough estimate of the state of orientation.

To obtain quantitative information the following approach has turned out to be very efficient [7]. First a background, mainly due to amorphous material, is separated from the measured scattering curves (Fig. 2). The residual "crystalline" scattering curves are then approximated by pseudo-Voigt functions which are further analy- sed in terms of a variety of parameters, all as a function of the distance from the surface. Apparent crystallite sizes $\mathrm{L}_{\mathrm{hkl}}$ (Fig. 3) and apparent Bragg distances $d_{\mathrm{kkl}}$ are determined from the width and angular position of reflections. Parameters characterizing the distribution (e.g. B $[2,8], G)$ and the orientation (e.g. $A_{110}[2], A_{130}$, C) of crystallite modifications (Fig. 4) are derived from relations between the intensities of reflections (Table 1 ).

Additional information on the texture (e.g. parameter $\mathrm{T}_{040}$, cf. Fig. 4) is available by means of a special analysis of intensities [6] if WAXS measurements of the same sample were performed with three different directions of the primary beam. 


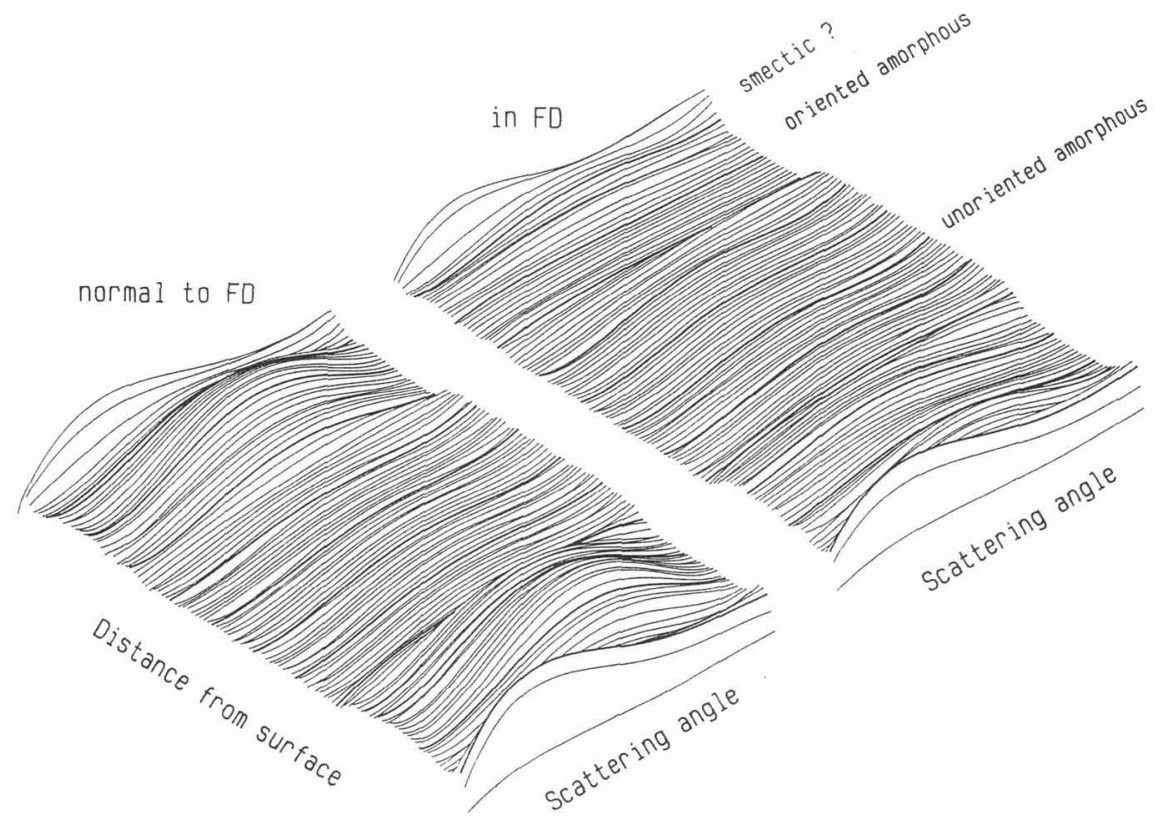

Fig. 2: These intensity maps show WAXS curves of the background due to amorphous and presumably also due to smectic material in the PP sample from Fig. 1, for different directions of the primary beam (on the left: normal to flow; on the right: parallel to flow). The different behaviour in the surface layers indicates an orientation of the amorphous phase.

Fig. 3: Apparent crystallite sizes $L_{h k t}$ plotted vs. the distance from surface. The data were derived from the scattering curves shown in Fig. 1, after subtracting the background (cf. Fig. 2) and approximating the residual "crystalline" curves by Pseudo-Voigt functions.

Some results of SAXS measurements on the PP KS10 plate from Fig. 1 are listed in Table II. The tabulated data reflect the dependence of long periods on the position in the moulding (distance from gate, distance from surface). It should be noted that the listed spacings refer to the equatorial direction.

\section{Conclusions}

The study has shown that our approach of scanning X-ray scattering delivers a gamut of detailed information about the layered structure

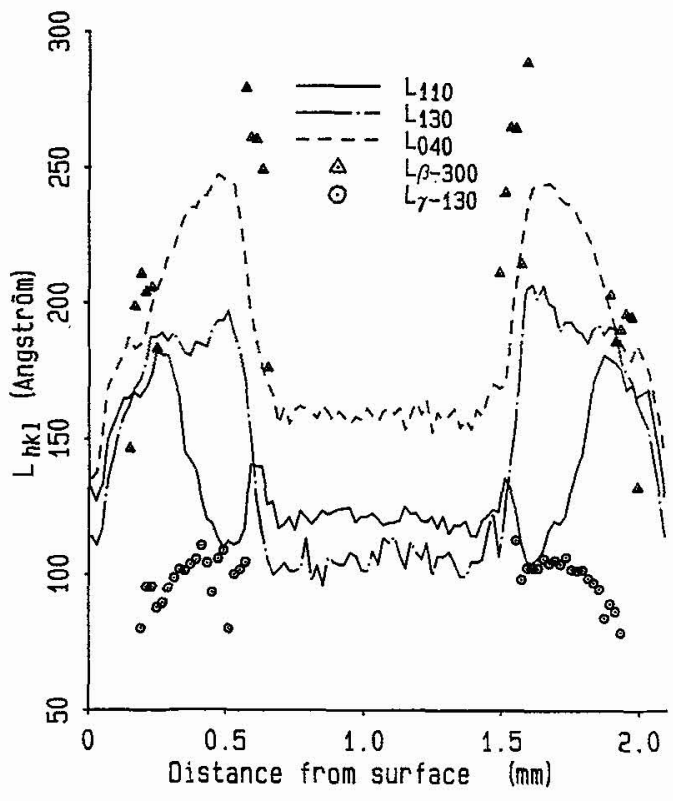


in cross-sections of plastic parts. The experimental procedure is simple and fast enough to be used successfully for routine analyses even with low-power $(<2.5 \mathrm{~kW}) \mathrm{X}$-ray generators.

This work was supported by the Austrian "Fonds zur Förderung der wissenschaftlichen Forschung" (project P7446).

\section{Table I}

Derivation of Parameters from the Intensities of Reflections

$$
\begin{gathered}
A_{110}=\frac{I_{110}}{I_{110}+I_{111}+I_{\overline{1} 31+041}} \\
A_{130}=\frac{I_{130}}{I_{130}+I_{111}+I_{\overline{1} 31+041}} \\
B=\frac{I_{\beta-300}}{I_{\beta-300}+I_{110}+I_{040}+I_{130}} \\
C=\frac{I_{040}}{I_{110}+I_{040}+I_{130}} \\
G=\frac{I_{\gamma-130}}{I_{\gamma-130}+I_{130}}
\end{gathered}
$$

Table II

Long periods in a plate from PP KS10

$\begin{array}{ccc}\begin{array}{c}\text { Distance } \\ \text { from gate } \\ (\mathrm{mm})\end{array} & \begin{array}{c}\text { from surface } \\ (\mu \mathrm{m})\end{array} & \begin{array}{c}\text { Long period } \\ (\AA)\end{array} \\ 20 & 180 & 131 \\ & 225 & 133 \\ & 300 & 142 \\ & 375 & 145 \\ 100 & 550 & 131 \\ & 50 & 104 \\ & 275 & 117 \\ & 590 & 108 \\ & 780 & 102 \\ & 1050 & 99\end{array}$

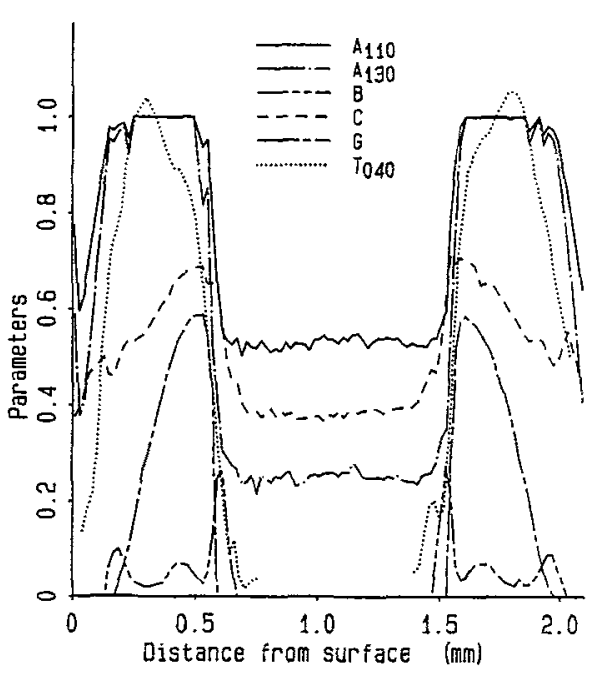

Fig. 4: Various distribution and orientation parameters of the PP sample from Fig. 1, plotted $v$ s. the distance from surface. Parameters $A_{110}$ and $A_{130}$ are measures of the orientation of $\alpha(110)$ and $\alpha(130)$ planes (values of $\approx 1$ indicate orientation parallel to the surface); parameter $C$ tends towards 1 when the crystallographic axis $a^{*}$ rather than axis $c$ points into the direction of flow. Parameters $B$ and $G$ quantify the relative amounts of $\beta$ - and $\gamma-P P$. Parameter $T_{040}$ is derived from the reciprocal width of orientation of a fiber axis and is a measure of the degree of orientation of $\alpha(040)$ planes.

\section{References}

[1] Mencik Z, Fitchmun DR (1973) J Polym Sci Polym Phys Ed 11:973-989

[2] Trotignon JP, Verdu J (1987) J Appl Polym Sci 34:1-18

[3] Fujiyama M, Wakino T, Kawasaki Y (1988) J Appl Polym Sci 35:29-49

[4] Fleischmann E, Zipper P, Jánosi A, Geymayer W, Koppelmann J, Schurz J (1989) Polym Eng Sci 29:835-843

[5] Zipper P, Jánosi A, Wrentschur E (1990) Österr Kunststoff Z 21:54-59

[6] Zipper P, Jánosi A, Wrentschur E, Abuja PM (1991) J Appl Cryst 24:702-708

[7] Zipper P, Jánosi, Wrentschur E, Knabl C, Abuja PM (1993) Österr Kunststoff Z 24: 162-165

[8] Turner-Jones A, Aizlewood JM, Becket RD (1964) Makromol Chem 75:134-158 